\title{
A Control Systems Course Project Serving as a Bridge to A Capstone Course and Research Projects
}

\section{Dr. Wei Zhan, Texas A\&M University}

Dr. Wei Zhan is an Associate Professor of Electronics Engineering Technology at Texas A\&M University. Dr. Zhan earned his D.Sc. in Systems Science from Washington University in St. Louis in 1991. From 1991 to 1995, he worked at University of California, San Diego and Wayne State University. From 1995 to 2006, he worked in the automotive industry as a system engineer. In 2006 he joined the Electronics Engineering Technology faculty at Texas A\&M. His research activities include control system theory and applications to industry, system engineering, robust design, modeling, simulation, quality control, and optimization.

\section{Dr. Byul Hur, Texas A\&M University}

Dr. B. Hur received his B.S. degree in Electronics Engineering from Yonsei University, in Seoul, Korea, in 2000, and his M.S. and Ph.D. degrees in Electrical and Computer Engineering from the University of Florida, Gainesville, FL, USA, in 2007 and 2011, respectively. In 2017, he joined the faculty of Texas A\&M University, College Station, TX. USA, where he is currently an Assistant Professor. He worked as a postdoctoral associate from 2011 to 2016 at the University Florida previously. His research interests include Mixed-signal/RF circuit design and testing, measurement automation, environmental \& biomedical data measurement, and educational robotics development.

\section{Dr. Boong Yeol Ryoo, Texas A\&M University}

Associate Professor Department of Construction Science Texas A\&M University

Ph.D., University of Wisconsin-Madison, U.S.A., 1995 M.S., University of Wisconsin-Madison, U.S.A., 1992 B.S., Yonsei University, Korea, 1983 


\title{
A Control Systems Course Project Serving as a Bridge to A Capstone Course and Research Projects
}

\begin{abstract}
"Control Systems" is an important course for Engineering Technology programs. An easy mistake to make in teaching the course is spending too much time in covering complex mathematical theory and solving theoretical problems. The applications of control system theory in applied research and capstone courses are sometimes overlooked by the instructors.

Many engineering technology programs are requiring their faculty members to conduct more research. At Texas A\&M University, engineering technology program faculty members are expected to perform well in both research and teaching. It is challenging to strike a balance between the two due to the reality of the heavy teaching load. This paper shows a practical case of how faculty members could successfully integrate teaching and research in the control systems course and a capstone course.

Three faculty members at Texas A\&M University formed a team and received an internal funding from the university to investigate the feasibility of using a custom-built drone platform for building safety inspection through autonomous and intelligent missions. One of the challenges is to fly a drone close to the surface of a building wall and maintain a constant distance.

A course project in Control Systems was designed to let students work in a related topic: How to control a robot to follow the contour of a wall while keeping a constant distance from the wall? After taking this course, some students chose to work on a capstone project to develop a drone that maintain distance from building wall. The drone would be controlled to survey the entire surface of a building, taking pictures of the surface while recording the coordinate information. The faculty members and their graduate students would use the drone developed by the capstone team to conduct research that involves using AI to detect damages in the surveyed building.

There are apparent similarities and differences between the course project and capstone project. As far as control is concerned, both projects require a sensor or sensors to detect the distance from the wall. The measured distance is used as a feedback signal to control some motors. In this aspect, the concepts of control for these two cases are similar. However, a drone is more difficult to control because it needs to fly in the three dimensional space while a robot moves around the ground.
\end{abstract}


Overall, the integration of research and teaching in this case helped the faculty members' research. At the same time, it benefitted the students in their learning in the Control Systems course as well as further learning through capstone courses. This approach of combining research and teaching can make the faculty members more productive as well as to make students to be more engaged in learning.

\section{Introduction}

There are three important subjects that will be discussed in this paper: (1) How to enhance teaching in a Control Systems course? (2) How to integrate the Control Systems and Capstone courses? (3) How to integrate research and teaching?

Many engineering technology (ET) programs offer Control Systems as an advanced course in their curricula. Control Systems course plays an important role since majority of engineering designs and projects involve in controlling devices. It also provides students with a higher-level and more abstract understanding of engineering systems. A transfer function can represent a circuit or a mechanical device. Transfer function-based analysis makes students understand how systems with mechanical, electrical, and other components can be analyzed and designed. However, teaching control systems to engineering students can be challenging due to the extensive use of mathematical concepts and tools such as Laplace transform, Z transform, differential equations, and difference equations. This challenge is even more serious for ET programs, since ET students typically prefer hands-on learning and they may not like to dive deep into learning abstract concepts and theoretic materials. Several educators tried to use practical applications and simulation tools to enhance student learning in control systems course $^{1-7}$. Others found that laboratories and course projects are important ingredients that can help students make the connection between the dry and abstract math concepts and practical applications $^{8-14}$.

Due to the multidisciplinary nature of control systems, it is common for students in capstone courses to apply control theory to their projects ${ }^{15-16}$. However, many students do not realize the importance of control systems and other basic math and science materials and how these can fit into other engineering courses ${ }^{20}$. They tend to hit a "reset button" after each and every course ${ }^{20}$. In general, a vertical integration of relevant courses in curricula is an important and challenging issue for engineering majors ${ }^{21}$. If possible, helping students to make a connection between the Control Systems course and their capstone projects can certainly be beneficial for their learning in both courses.

For engineering faculty members, balancing research and teaching is a delicate issue.

Traditionally, ET faculty members have higher teaching load and lower expectation for research compared to their engineering counterparts. In recent years, some ET programs are increasingly moving towards more research activities. Research productivity carries higher weight than before. This has created some anxiety among ET faculty members. Jordan (2017) presented a 
paper on using undergraduate research to teach advanced materials ${ }^{17}$. Grave and Hager III (2007) successfully integrated research, teaching and entrepreneurship in their project ${ }^{18}$. Zhan (2014) presented a result in integration of research and education involving undergraduate research. The challenge is to increase research productivity without sacrificing quality of educational experience for students. Integration of teaching and research is one of the proposed solution to this challenge.

Inspired by the above mentioned educational research work in the literature, the authors tried to combine a course project in the control systems course, a capstone project, and research activity of faculty members into a seamlessly integrated teaching and research effort. The execution detail of the integration is discussed in this paper.

\section{Research project}

To foster new research and scholarship at Texas A\&M University, the T3: Texas A\&M Triads for Transformation seed-grant was initiated in 2018 by the university. It is a multidisciplinary program that is a part of the President's Excellence Fund designed to further Texas A\&M University's commitments to the three pillars of advancing transformational learning; enhancing discovery and innovation and expanding impact on our community, state, nation, and world. Faculty members were required to form "triad" of three members to apply for funding of $\$ 30,000$ for each project. The university is investing $\$ 100$ million for the next 10 years, approximately $\$ 3$ million annually in this effort. Every year, 100 interdisciplinary projects are funded by this initiative.

The three authors formed a triad to compete for the seed-grant and the project has been funded for a period of 24 months. The research topic of the funded project is to use drones to conduct building inspection. Currently, building inspections are conducted manually using methods such as suspended platform inspection and grappling inspection as illustrated in Fig. 1.
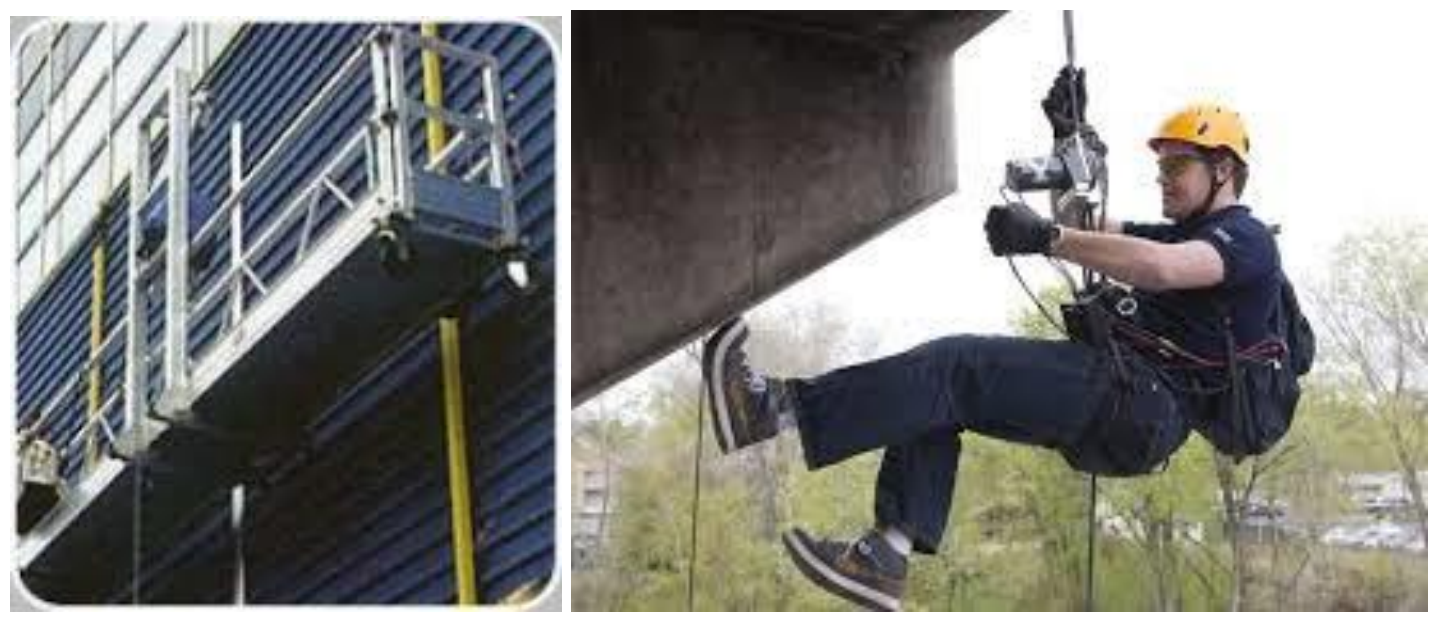

Fig. 1. Suspended platform inspection (Left) and grappling inspection (Right) 
These manual inspection methods are time consuming, unsafe, or requiring heavy equipment. The proposed method in the research project is to use drones to conduct building inspection.

There are several tasks that need to be done in this project. First, a custom made drone needs to be built, it should have the capability to follow the contour of building walls, as illustrated in Fig. 2. The wall may not be flat. It should be controlled by an on-board micro-controller that can communicate wirelessly using a remote controlled joystick. The embedded system must have a certain level of artificial intelligence to detect cracks and other damages on the building wall. Once the damages are identified, pictures will be taken and saved to a flash card for further offline analysis. Coordinates of the damaged surface will be recorded with the pictures.

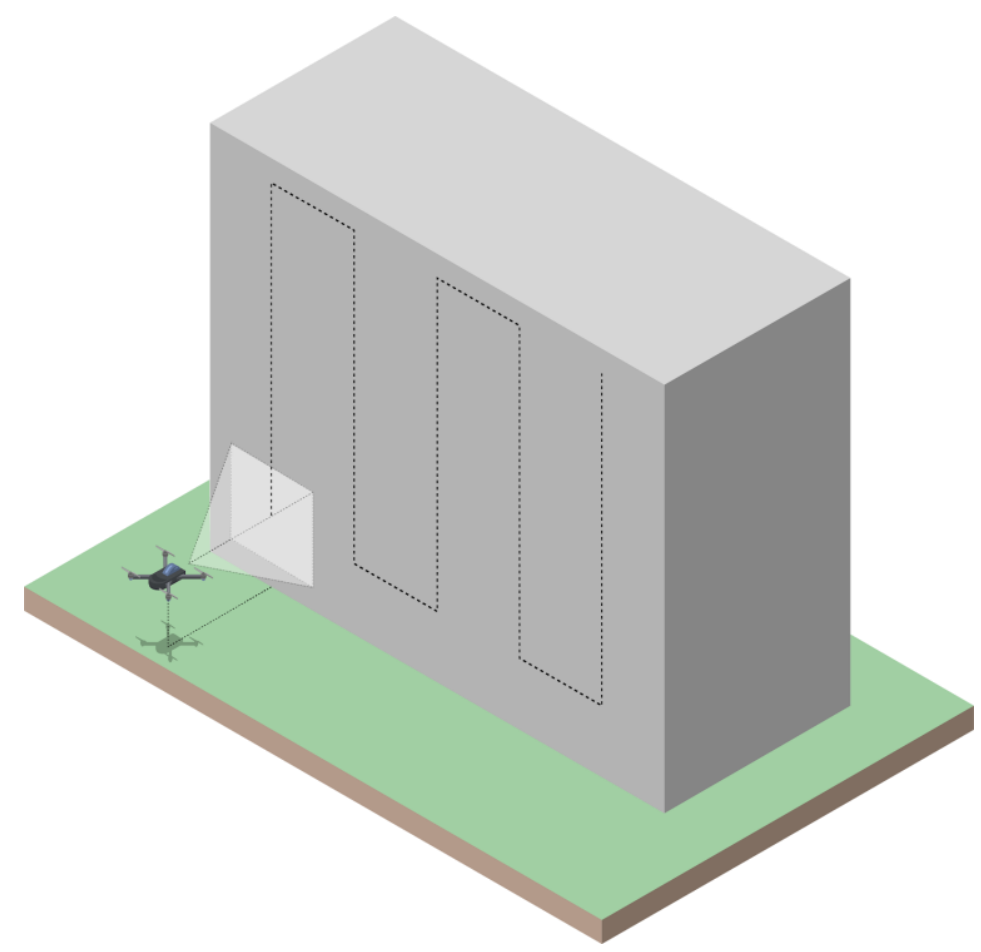

Fig. 2. Drone inspection

\section{Capstone project}

After careful study of the required tasks for the research project, a decision was made to give a portion of the tasks to a capstone team. ET students have strength in building functioning prototypes. The custom designed drone will be built by the capstone team in two semesters. The basic functionalities include flying the drone up and down following the contour of the building wall, being able to take pictures of the entire surface, wirelessly over a remote control unit; and recording the $\mathrm{x}, \mathrm{y}, \mathrm{z}$ coordinate using GPS and sensors to measure heights.

The capstone team was tasked to size the system components including motor, propellers, batteries, camera, frame, and micro-controller. Propeller guards will be designed and fabricated using a 3D printer by the capstone team to provide additional safety for the drone operation. 
Texas A\&M University has strict regulations on drone operation on campus. Flight license and training are mandatory.

The artificial intelligent algorithm for building damage detection is beyond the scope of undergraduate capstone design course, as a result, this portion of the research is planned to be carried out by faculty members and graduate students.

The main control-related design challenge is to fly the drone at a fixed distance away from the building surface. This is a closed loop control system with the distance measurement as the feedback. The speeds of the four motors on the drone are controlled based on the feedback to maintain constant distance between the drone and the building wall surface. The drone must be able to avoid collision with any part of the building wall, this is particularly important when the surface of the wall is not flat. The electronic speed control unit with a PID (proportionalintegral-derivative) type of controller is used to achieve certain performance specification. Students need to design and operate the drone in different operation modes such as manual operation through the wireless communication from the joystick control and auto pilot operation.

One of the students in the capstone team took the control systems course during the first semester of the capstone courses. The capstone projects are two semester courses in this department. The capstone team are making a fast progress, partly because of the experience gained in the course project in Control Systems.

\section{Course project}

In the syllabus of the Control Systems course, the course description, course objectives and learning outcomes were given as follows.

\section{Course Description}

Components, principles, and techniques fundamental to automated control systems. Study of transfer functions, network analysis using Laplace transforms, $\mathrm{Z}$ transforms, feedback control systems theory, digital computer simulation, and computer-based controls systems.

\section{Course Objectives}

To introduce fundamentals of real-time closed-loop continuous and discrete control using proportional, integral, and derivative control, sensors, and electronics. Applying these principles to the computer-based design and simulation of control systems that are then implemented and tested using real-time, graphically-oriented software development environment.

\section{Learning Outcomes}

At the completion of this course, students will be able to:

- define and use the terminology associated with control systems; 
- explain the mathematical model for first and second degree plant transfer function;

- design closed-loop control systems for simple applied engineering problems;

- employ virtual instrumentation software platforms to simulate closed-loop control systems;

- identify, define and explain classical and digital control systems.

Tentative Course Schedule

\begin{tabular}{|c|c|c|}
\hline Week & Lecture & Lab \\
\hline 1 & $\begin{array}{l}\text { Class Policy \& Objectives, Open-loop and Closed-Loop, } \\
\text { PID Control System }\end{array}$ & $\begin{array}{l}\text { Lab safety; Program with LabVIEW. Interface and } \\
\text { Block Diagram. }\end{array}$ \\
\hline 2 & Transfer Functions, Block-Diagram & Lab 1: Using LabVIEW Control Toolbox \\
\hline 3 & Laplace Transforms \& Properties & Lab 2: Discrete LED Demo with MyRIO \\
\hline 4 & Inverse Laplace, Real, Identical Roots & Lab 3: Motor Driving with MyRIQ \\
\hline 5 & First Order System, Time Constant, Final Value Theorem & $\begin{array}{l}\text { Lab 4: H-Bridge and Geared Motor with Feedback } \\
\text { Control }\end{array}$ \\
\hline 6 & PID control design for First Order System & $\begin{array}{l}\text { Lab 5: Sonic Range Finder and Geared Motor with } \\
\text { Feedback Control }\end{array}$ \\
\hline 7 & $\begin{array}{l}\text { Inverse Laplace (Imaginary Roots), Second } \\
\text { Order System }\end{array}$ & Lab 6: Improvement of Your Robot Car \\
\hline 8 & $\begin{array}{l}\text { Damping Ratios, Natural Frequency. } \\
\text { Overdamped, underdamped, Critically } \\
\text { Damped. Settling Time, Overshoot, Rise Time, Peak Time. }\end{array}$ & $\begin{array}{l}\text { Lab 7: Potential Field Built by Ambient Light } \\
\text { Sensor }\end{array}$ \\
\hline 9 & Problem Solving / Review Midterm Exam (March 19) & Final Project \\
\hline 10 & $\begin{array}{l}\text { Continuous PID Design, P, I, D, PI, PD Controllers for } \\
\text { Second Order System }\end{array}$ & Final Project \\
\hline 11 & Continuous PID Control Design Continued & Final Project \\
\hline 12 & Higher Order Systems. Root Locus Design. Bode Plot. & Final Project \\
\hline 13 & Digital Control System, Z-Transform Properties & Final Project \\
\hline 14 & Discrete Closed-loop Control System & Final Project \\
\hline 15 & Problem Solving / Final Exam Review & Final Project Demo \\
\hline
\end{tabular}

Fig. 3. Course Schedule

The research project is about solving a real-world problem, which can provide students in the control system course an opportunity to make a direct connection between the abstract math concepts and problem solving. A course project related to the research is consistent with the learning outcomes, course objectives, and the schedule for the final project. However, it is important to find the appropriate scope for a course project. If the scope of the research project is too large for students in a one-semester course, it may not produce a good result. For instance, it would be too much to have a course project like the entire capstone project discussed earlier.

Controlling a drone is an interesting and relevant topic in the control systems course. However, there is a limitation about the use of drones in classes. Due to the university requirement of drone license for on-campus operation, it is not realistic for all students to go through the training and get the license. To get around this issue, a decision was made to use a Zumo 32U4 robot platform, as shown in Fig. 4, for the course project. It is a low-cost platform with several optional sensors, and it has distance measurement sensors. 


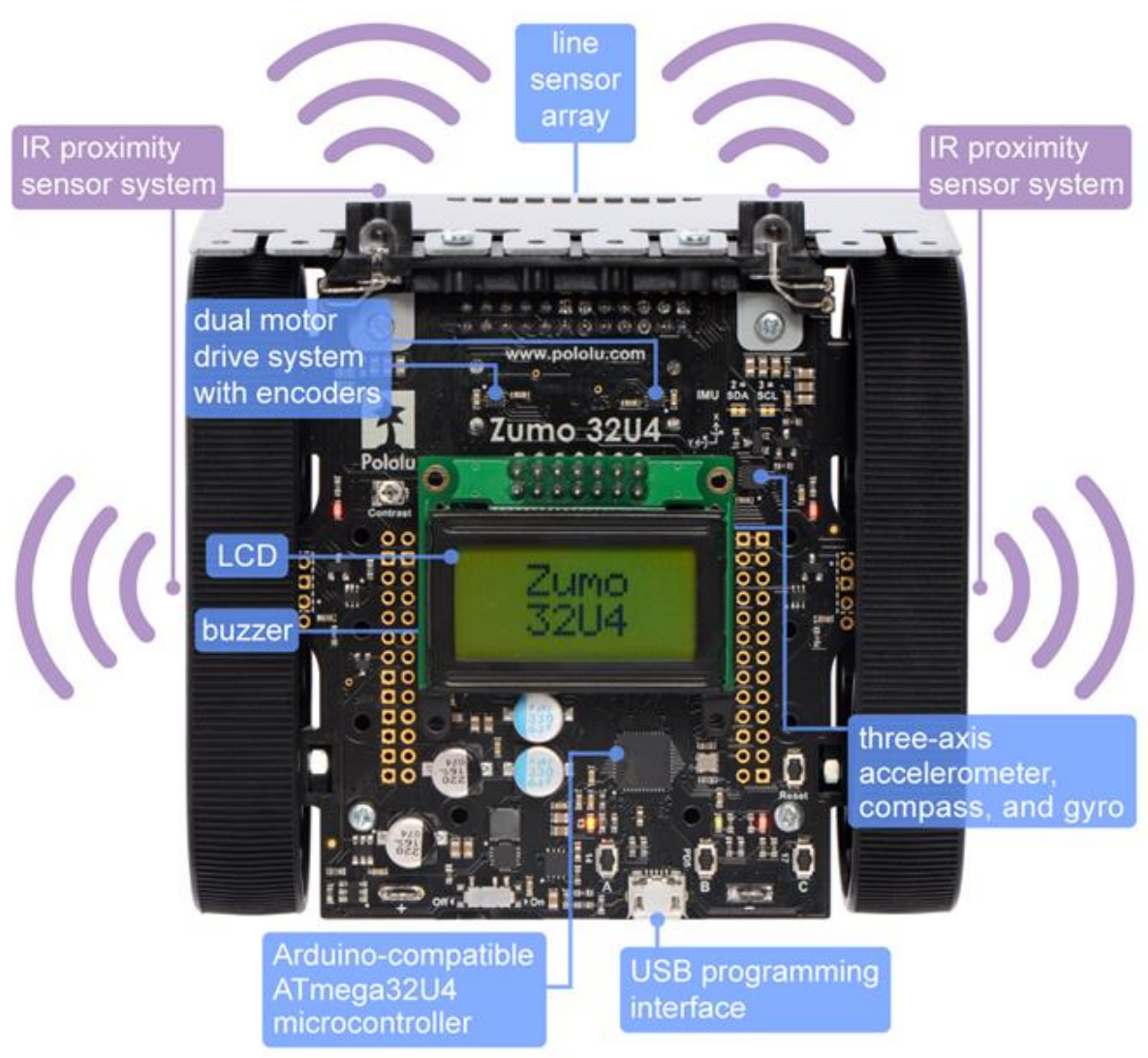

Fig. 4. Zumo 32U4 Robot platform

As a course project, this educational robot platform was used instead. The objective of the course project was to control the robot so that it could move along a wall while maintaining a constant distance between the robot and the wall. The contour of the wall is not a flat surface, as illustrated in Fig. 5.

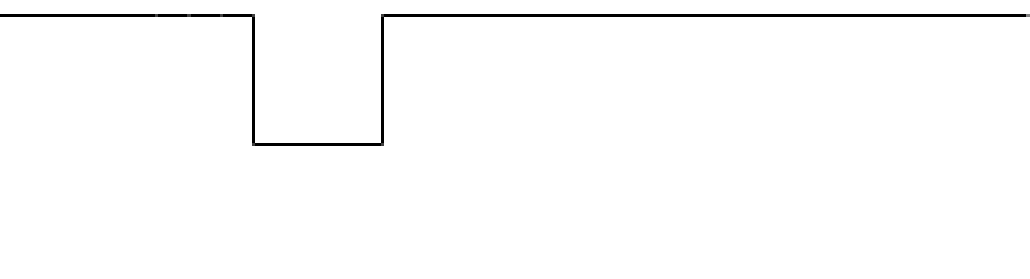

Fig. 5. Contour of a wall

As far as control is concerned, the robot platform and drones are very similar: they both have sensors that provides distance between the unit and nearby objects; the control actions are to control the motor speeds. In addition to the PID controller design, the algorithm must include methods to detect that the contour of the wall has a sudden change, such as a 90 degree turn to the left or right. 
The laboratories for the control systems course were modified to help students get familiar with the Zumo 32U4 robot platform [22]. Students first learned how to program the robot using the open-source Arduino IDE to perform the following basic operations:

- moving forward

- moving backward

- making left turn

- making right turn

- turning the robot uphill on a slanted surface

- stopping when there is an object in front

- reading and decoding the feedback signal from the accelerometer and proximity sensors.

From theoretical standpoint of view, the course project could be seen as a very straightforward PID controller design problem. However, students learned that there were many practical issues involved in the design. Noise in the feedback signals was one of the problems they had to deal with. Students found the use of a digital filter significantly reduced the impact of the noise. In addition to the PID controller, they found that custom algorithms were necessary to handle different situations such as the wall contour changing suddenly and the robot needed to perform a sharp 90 degree turn to the left or right. Another problem was the interference to the accelerometers when the Zumo robot rapidly changed its movement. If not careful, the accelerometers could falsely detect an angle as high as 20 degrees.

\section{Conclusions and future work}

This paper discusses a case study where a part of the research project was used as capstone stone project and a part of the capstone project was used as laboratory material and a course project in a control systems course. It worked well for all three areas: teaching the control systems course with real-world problems; integrating control systems course and capstone course; and research project. Students in the control systems course were more interested to learn the abstract concept with real-world background. The control system course project helped the capstone team to learn how to design a PID controller and control logic to surface contour change detection. The capstone team is building a prototype with basic functionalities that allows additional research work to be done. However, the COVID-19 pandemic has cause the capstone team to pause their effort of correcting design mistakes and testing their final prototype.

For faculty members involved in this effort, some common areas between teaching and research were found. Education and research are integrated resulting in higher productivity in both areas. A conference paper was presented with the main subject of developing a drone for building surveying ${ }^{23}$. This is a direct evidence that the effort to combine teaching and research was successful. 
To enhance the teaching of the control systems course, it is planed to include modeling and simulation for the PID controller of the robot platform. After the current capstone project is completed, a new version of underwater robot can be the subject of the next capstone project. The research scope can also be extended to include underwater surveying of structures such as bridges, ships, and piers.

\section{References}

1. Bishop, R., \& Dorf, R. (2001, June), Teaching Modern Control System Analysis And Design, Paper presented at 2001 Annual Conference, Albuquerque, New Mexico. https://peer.asee.org/9871

2. Krauss, R. W., \& Ali, A., \& Lenz, A. L. (2017, June), Teaching Dynamic Systems and Control without Dynamics, Paper presented at 2017 ASEE Annual Conference \& Exposition, Columbus, Ohio. https://peer.asee.org/28911

3. Eke, E. M. (2015, June), Using Simulink, Matlab, and LEGO Mindstorms to Teach a Project-Based Control Systems Design Course Paper presented at 2015 ASEE Annual Conference \& Exposition, Seattle, Washington. 10.18260/p.25016

4. Tan, L., \& Jiang, J. (2013, June), Teaching System Modeling and Feedback Control Systems: A Multidisciplinary Course in Mechanical Engineering and Electrical Engineering Paper presented at 2013 ASEE Annual Conference \& Exposition, Atlanta, Georgia. https://peer.asee.org/19021

5. Raviv, D., \& Roskovich, G. J. (2014, June), An Intuitive Approach to Teaching Key Concepts in Control Systems Paper presented at 2014 ASEE Annual Conference \& Exposition, Indianapolis, Indiana. https://peer.asee.org/20064

6. Yoder, J., \& Rider, M., \& Hurtig, J. (2004, June), Providing Hands On Experiences In A Mechanical Engineering Controls Systems Course Paper presented at 2004 Annual Conference, Salt Lake City, Utah. https://peer.asee.org/13232

7. Sriraman, V., \& Um, D. (2004, June), Teaching Basic Control Systems Theory Using Robots Paper presented at 2004 Annual Conference, Salt Lake City, Utah. https://peer.asee.org/13488

8. David R. Loker, Robert Weissbach, and Adam Henry, "Conveyor Control System Project," 2011 ASEE Annual Conference \& Exposition.

9. David Loker, "Elevator Control System Project," 2010 ASEE Annual Conference \& Exposition.

10. Sriram Sridharan and Ben Zoghi, "Control System Project: Rfid Based Access Human Transporter," 2009 ASEE Annual Conference \& Exposition. 
11. Jack, H. (2003, June), Teaching Mechanical Students To Build And Analyze Motor Controllers Paper presented at 2003 Annual Conference, Nashville, Tennessee. https://peer.asee.org/12091

12. Houshangi, N. (2007, June), Establishing A Multidisciplinary Control System Laboratory Paper presented at 2007 Annual Conference \& Exposition, Honolulu, Hawaii. https://peer.asee.org/2456

13. Li, P., \& Waletzko, D., \& Durfee, W. (2005, June), At-Home System and Controls Laboratories Paper presented at 2005 Annual Conference, Portland, Oregon. https://peer.asee.org/15079

14. Schmidt, D., \& Plett, G. (2002, June), Multidisciplinary Digital Control Systems Laboratory Paper presented at 2002 Annual Conference, Montreal, Canada. https://peer.asee.org/11017

15. Jariwala, A. S., \& Zhou, F., \& Zeng, W., \& Li, S., \& Drexler, C., \& Wang, C., \& Zhang, H., \& Jiao, R. J. (2014, June), Case Study of a Multidisciplinary Engineering Capstone Design Project: Electric Drive Control System Paper presented at 2014 ASEE Annual Conference \& Exposition, Indianapolis, Indiana. https://peer.asee.org/20154

16. Yousuf, A., \& Mustafa, M. A. (2012, June), Capstone Project: Electronic Name Tag System Paper presented at 2012 ASEE Annual Conference \& Exposition, San Antonio, Texas. https://peer.asee.org/21044

17. Jordan, W. M. (2017, June), Using Undergraduate Research to Teach Advanced Materials Paper presented at 2017 ASEE Annual Conference \& Exposition, Columbus, Ohio. https://peer.asee.org/29093

18. Grave, I., \& Hager III, N. (2007, June), Integration Of A Research/Teaching/Entrepreneurship Model At Elizabethtown College Paper presented at 2007 Annual Conference \& Exposition, Honolulu, Hawaii. https://peer.asee.org/2464

19. Zhan, W., "Research Experience for Undergraduate Students and its Impact on STEM Education," Journal of STEM Education: Innovation and Research, Vol. 15, No. 1, 2014, pp. 32-38.

20. Avitabile, P., \& Pennell, S., \& White, J., \& Van Karsen, C. (2006, June), An Interwoven Multisemester Dynamic Systems Project To Integrate Stem Material Paper presented at 2006 Annual Conference \& Exposition, Chicago, Illinois. https://peer.asee.org/417

21. Zhan, W., Goulart, A., Morgan, J. A., and Porter, J. R., "Vertical and horizontal integration of laboratory curricula and course projects across the electronics Engineering Technology program," American Journal of Engineering Education, Vol. 2, No. 2, Fall 2011, pp-67-80. 
22. Pololu Robotics \& Electronics, “Zumo 32U4 Robot,” on-line: https://www.pololu.com/category/170/zumo-32u4-robot

23. Hur, B., Ryoo, B. Y., Zhan, W., Bustos, C., Consuelo, G., Orozco, L., and Vazquez, R., "Progress in Autonomous Drone Prototype Development for Scanning Exterior Damage of Buildings," Industry, Engineering \& Management Systems Conference, March 15-17, Clearwater Beach, FL. 